\title{
AVALIAÇÃO DA CONTAMINAÇÃO POR ORGANOFOSFORADOS EM ÁGUAS SUPERFICIAIS NO MUNICÍPIO DE RONDINHA - RIO GRANDE DO SUL
}

\section{Francieli Três Griza*, Karen Saldanha Ortiz e Douglas Geremias}

Instituto de Toxicologia, Pontifícia Universidade Católica do Rio Grande do Sul, Av. Ipiranga, 6681, 90619-900 Porto Alegre RS. Brasil

\section{Flávia Valladão Thiesen}

Faculdade de Farmácia e Instituto de Toxicologia, Pontifícia Universidade Católica do Rio Grande do Sul, Av. Ipiranga, 6681, 90619-900 Porto Alegre - RS, Brasil

Recebido em 29/6/07; aceito em 30/4/08; publicado na web em 19/9/08

\begin{abstract}
EVALUATION OF THE ORGANOPHOSPHATES PESTICIDES CONTAMINATION IN SUPERFICIAL WATER OF RONDINHA - RIO GRANDE DO SUL. Water pollution is a serious environmental problem. In Rondinha, Rio Grande do Sul, on a small area planted with tobacco, it has been using organophosphates pesticides. The purpose of this study was to evaluate the organophosphates pesticides contamination of the superficial water in this municipality. The samples collected in fifteen places were evaluated by the method of organophosphates acethylcolinestherase inhibition. In five samples the organophosphates levels were above the limit established by CONAMA, indicating the necessity of arrangements that allow reducing the risk of the population and the environment contamination.
\end{abstract}

Keywords: water; organophosphates; acethylcolinestherase inhibitors.

\section{INTRODUÇÃO}

A água é o elemento fundamental da vida. Seus múltiplos usos são indispensáveis a um largo espectro das atividades humanas, onde se destacam, entre outros, o abastecimento doméstico e industrial, a irrigação agrícola, a geração de energia elétrica e as atividades de lazer e recreação, bem como a preservação da flora e fauna..$^{1-3} \mathrm{~A}$ poluição das águas constitui um dos mais sérios problemas ecológicos da atualidade. A interferência do homem, de forma concentrada, na geração de despejos domésticos ou industriais, ou de forma dispersa, em atividades como a aplicação de agrotóxicos no solo, contribui para a introdução de compostos na água, afetando a sua qualidade. ${ }^{4,5}$ Por isso, o modo como o homem usa e ocupa o solo tem uma implicação direta na qualidade da água. ${ }^{1,5}$

Os agrotóxicos estão entre os principais instrumentos do atual modelo de desenvolvimento da agricultura brasileira mas, devido aos efeitos adversos que podem causar à exposição humana e ao meio ambiente, é crescente a preocupação com esses produtos na contaminação das águas superficiais e subterrâneas. ${ }^{5}$ Mesmo em concentrações baixas, os agrotóxicos representam riscos para algumas espécies de organismos aquáticos que podem concentrar estes produtos até 1000 vezes, transferindo os efeitos tóxicos para outros organismos da cadeia alimentar. ${ }^{6-8}$ Estudos desenvolvidos em várias regiões do mundo têm mostrado que a porcentagem dos produtos utilizados na agricultura que atinge os ambientes aquáticos é geralmente baixa em parte devido ao efeito de diluição. Mas não exclui a possibilidade de que concentrações muito altas venham a ocorrer após chuvas, especialmente quando as áreas próximas a córregos foram recentemente tratadas com altas quantidades de agrotóxicos. ${ }^{6}$

A preocupação com a contaminação de ambientes aquáticos aumenta, principalmente, quando a água é usada para o consumo humano. A União Européia estabeleceu o valor de $0,1 \mu \mathrm{g} / \mathrm{L}$ como concentração máxima permitida de qualquer agrotóxico em águas destinadas ao consumo humano, independente de sua toxicidade. ${ }^{6,9}$

*e-mail: francitres@yahoo.com.br
A Organização Mundial da Saúde (OMS) também estabelece níveis máximos em água baseados em estudos toxicológicos e epidemiológicos para agrotóxicos, porém para os organofosforados como parationa metílica e malationa os valores não foram estabelecidos em razão de ocorrerem nas águas potáveis concentrações abaixo daquelas em que podem ocorrer efeitos tóxicos. ${ }^{10}$ No Brasil, de acordo com a Portaria $\mathrm{n}^{\circ} 518$ de 25 de março de 2004 do Ministério da Saúde, o limite para organofosforados é de 15 ou $20 \%$ de inibição da acetilcolinesterase, quando a enzima utilizada for proveniente de insetos ou mamíferos, respectivamente. ${ }^{11}$ A Resolução n 357 de 17 de março de 2005 do Conselho Nacional do Meio Ambiente (CONAMA) estabeleceu limites máximos dos contaminantes em águas que dependem do seu destino, especificando nas águas de classe I e II os limites de 0,04 $\mu \mathrm{g} / \mathrm{L}$ em parationa metílica e de $0,1 \mu \mathrm{g} / \mathrm{L}$ em malationa. ${ }^{12}$

No município de Rondinha, Rio Grande do Sul, Brasil, os organofosforados são utilizados principalmente em lavouras de fumo cultivadas em pequenas propriedades de economia familiar, com média de 19,5 ha. Estas lavouras representam uma importante fonte de renda por unidade de área. ${ }^{13}$ Rondinha situa-se na região do Alto-Médio Uruguai, ao norte do Rio Grande do Sul, a uma altitude de $440 \mathrm{~m}$ acima do nível

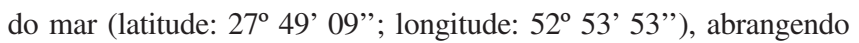
uma área de $252 \mathrm{~km}^{2}$. Em 2007, a população era estimada em 5.674 habitantes. ${ }^{14}$ Este município pertence à Micro Bacia Hidrográfica do Rio da Várzea, sendo banhado por seis riachos, onde se destacam os Rios Sarandi (120 km) e Lambari $(20 \mathrm{~km})$, que passam pelo centro da cidade, onde se unem. ${ }^{13,15}$ Segundo a Resolução no 357/2005 (CONAMA), as águas dos arroios e rios do município pertencem à classe II (águas que podem ser destinadas ao abastecimento humano, após tratamento convencional). ${ }^{12}$ Nos últimos anos, o regime pluviométrico médio foi de $1.787 \mathrm{~mm}$, com chuvas distribuídas normalmente nas quatro estações do ano. A Companhia Riograndense de Saneamento (CORSAN) abastece $100 \%$ dos domicílios da cidade através de uma estação de tratamento de água (tratamento simplificado). No interior do município, todas as famílias rurais possuem água potável de poço artesiano. Em Rondinha também há fontes de água mineral, que a população costuma consumir de forma direta. ${ }^{13}$ 
A economia de Rondinha é baseada principalmente na produção de leite de vaca e na agricultura, sendo as principais culturas soja, milho, trigo, feijão e fumo. ${ }^{14}$ Nessas culturas há aplicação de organofosforados; entretanto, há um maior emprego destes inseticidas nas lavouras de fumo, principalmente entre os meses de setembro a dezembro. Em 2003, a área plantada de fumo foi de 130 ha (média de 1,2 ha por propriedade), aproximadamente $0,83 \%$ da área agricultável do município, representando $1,91 \%$ do ICMS. ${ }^{13}$

Os agrotóxicos organofosforados são ésteres fosfóricos e constituem uma classe importante de inseticidas usados atualmente no combate a diversos tipos de pragas na agricultura. ${ }^{9}$ No Sistema de Informações sobre Agrotóxicos da Agência Nacional de Vigilância Sanitária (ANVISA) estão registrados 38 ingredientes ativos da classe dos organofosforados, entre eles, acefato, bromofós, clorpirifós, diazinona, diclorvós, etoprofós, fenclorfós, fentiona, malationa, metamidofós, parationa metílica, pirimifós e temefós. ${ }^{16}$

Os organofosforados possuem uma eficiente atividade inseticida, devido a sua característica de inibir irreversivelmente a enzima acetilcolinesterase no sistema nervoso, que tanto atua em insetos quanto em mamíferos. ${ }^{17}$ No homem, os organofosforados são absorvidos através de todas as vias, atingindo altas concentrações em tecido adiposo, fígado, rins, glândulas salivares, tireóide, pâncreas, pulmões, estômago, intestinos e, em menor proporção, no sistema nervoso central (SNC) e músculos. Entretanto, os organofosforados não se acumulam no organismo humano, sendo facilmente biotransformados no fígado. A excreção destes compostos e de seus produtos de biotransformação é bastante rápida, ocorrendo em maior parte pela urina e em pequenas proporções pelas fezes, quase sempre nas primeiras $48 \mathrm{~h}$. Os maiores níveis de excreção ocorrem nas primeiras 24 h após a absorção. ${ }^{18,19}$

No meio ambiente estes compostos são degradados no período de 1 a 12 semanas, ${ }^{18,19}$ no entanto, existe a possibilidade de permanecerem na água resíduos e subprodutos em níveis relativamente nocivos para o consumo humano. ${ }^{9,17}$

A intoxicação aguda por organofosforados atinge o sistema nervoso autônomo, provocando efeitos muscarínicos (bradicardia, hipotensão arterial, perda de apetite, náuseas, vômitos, dores abdominais, diarréia, aumento da diurese, miose e broncoconstrição); o sistema somático, resultando em efeitos nicotínicos (cãibras, contrações involuntárias e tremores da musculatura esquelética) e o SNC, causando agitação, confusão mental, convulsões, depressão respiratória, incoordenação dos movimentos, torpor e coma, entre outros..$^{9,18,19}$

A exposição crônica a baixas doses de organofosforados também pode provocar efeitos importantes, pois pode causar ansiedade, ataxia, confusão mental, depressão, dificuldade de concentração, fala arrastada, febre, fraqueza generalizada, insônia, labilidade emocional, nistagmo, perda de memória, paralisias, parestesias, polineurite, psicose, sonambulismo, tontura, transtorno bipolar, tremores, zumbidos, ${ }^{20-24}$ sinais e sintomas de Parkinsonismo, ${ }^{25}$ lesões maculares comprometendo a visão, ${ }^{26}$ entre outros. Existe, ainda hoje, muita controvérsia com relação a alguns efeitos tóxicos crônicos para o ser humano, como teratogenicidade, mutagenicidade e carcinogenicidade..$^{4,27-29}$ Isto indica a importância de desenvolver estudos sobre a presença de resíduos no ambiente e seus efeitos sobre a saúde. ${ }^{17}$

Vários estudos demonstraram que, devido aos processos naturais de movimento das águas, resíduos de organofosforados são transportados para compartimentos de acumulação no ambiente, contaminando recursos hídricos superficiais e subterrâneos utilizados no abastecimento de água potável dos municípios. ${ }^{8,9,17,30,31} \mathrm{O}$ transporte de agrotóxicos no ar atmosférico também pode ser uma das fontes de contaminação de águas superficiais. ${ }^{6}$ Assim, a utilização de agrotóxicos e seus possíveis efeitos ao ambiente e à saúde humana tornaram-se uma grande preocupação da comunidade científica, principalmente quando o recurso hídrico potencialmente contaminado pode ser utilizado para consumo humano. ${ }^{4,17,32}$

Na sua maioria, as metodologias de determinação dos agrotóxicos em água exigem que se efetue previamente a extração e pré-concentração destes compostos. A determinação da atividade da acetilcolinesterase por meio da espectrofotometria é considerada um importante exame laboratorial para confirmação do diagnóstico de intoxicação e para contaminação de águas, pois é um método simples, de baixo custo e já validado. ${ }^{19}$ No entanto, este método não permite identificar o inseticida, nem diferenciar organofosforados de carbamatos. Os métodos que identificam e quantificam os organofosforados geralmente são métodos cromatográficos precedidos por extração líquido-líquido (ELL) ou extração por fase sólida (EFS). A ELL envolve grandes quantidades de solventes, gerando maior volume de resíduos e risco de exposição dos analistas, além disso, a análise é demorada; já a EFS, embora use menor quantidade de solventes e possua uma alta recuperação do analito, tem como desvantagens o custo e a não reutilização dos materiais. Além disso, técnicas cromatográficas necessitam de pessoal especializado e maior investimento para aquisição e manutenção dos equipamentos quando comparadas a técnicas espectrofotométricas.,9

Dessa forma, o objetivo deste estudo foi avaliar a possível contaminação de águas superficiais potencialmente utilizadas para consumo humano e animal, devido ao uso de agrotóxicos organofosforados em regiões com cultura do fumo do município de Rondinha.

\section{PARTE EXPERIMENTAL}

\section{Locais de amostragem e coleta das amostras de água}

A coleta da água bruta superficial do município de Rondinha-RS para avaliar a possível presença de agrotóxicos organofosforados foi realizada em 4/10/2004, em uma fonte de água mineral e em rios e arroios na cidade e no interior do município (Figura 1S - Material Suplementar), locais escolhidos devido à maior probabilidade de impacto agrícola (Tabela 1). O interior deste município é dividido em várias comunidades denominadas Linhas. As 15 amostras de água foram coletadas em vidros âmbar $(100 \mathrm{~mL})$ previamente esterilizados,

Tabela 1. Locais de coleta das amostras de água no município de Rondinha, RS

\begin{tabular}{lcc}
\hline Amostra & Pontos de coleta & Localização/ Propriedade \\
\hline 1 & $\begin{array}{c}\text { Fonte de água } \\
\text { mineral }\end{array}$ & Cidade (Praça Pe. Eugênio \\
$2 *$ & Medicheschi) \\
3 & Rio Lambari & Linha Lambari / "I.D." \\
4 & Rio Lambari & Linha Lambari / "I.D." \\
5 & Rio Lambari & Linha Lambari / "O.D." \\
$6 *$ & Rio Lambari & Cidade (Rua Julio Mailhos) \\
7 & Rio Sarandi & Linha Schio / "J.B." \\
8 & Rio Sarandi & Linha Schio / "S.B." \\
9 & Rio Sarandi & Linha Schio / "J.B." \\
$10 *$ & Rio Sarandi & Cidade (Parque Municipal de \\
11 & Arroio Seco & Rondinha) \\
12 & Arroio Seco & Linha Lajeado Seco / "V.D." \\
$13 *$ & Arroio Seco & Linha Lajeado Seco / "E.D.R." \\
14 & Arroio Araçá & Linha Araçá Santo Antônio / "A.O." \\
15 & Arroio Araçá & Linha Araçá Santo Antônio / "A.O." \\
\hline
\end{tabular}

* Amostras de água coletadas antes das plantações. 
lavados previamente três vezes com a mesma água a ser amostrada. Em seguida, introduziram-se os frascos na água a uma profundidade de 4 a $5 \mathrm{~cm}$ até seu completo preenchimento, evitando-se locais turbulentos e próximos às margens. As amostras, devidamente identificadas, foram mantidas sob refrigeração à temperatura de $4{ }^{\circ} \mathrm{C}$ até o momento da análise. ${ }^{33,34}$ Durante a coleta, os proprietários das áreas em que as amostras foram coletadas deram informações a respeito do uso de agrotóxicos da classe dos organofosforados e carbamatos.

\section{Método analítico}

Para a determinação da contaminação por agrotóxicos inibidores da acetilcolinesterase nas águas superficiais utilizou-se o kit produzido pelo Departamento de Saneamento e Saúde Ambiental da Fundação Oswaldo Cruz, que desenvolveu uma metodologia para água e alimentos baseada em preparações da enzima acetilcolinesterase capaz de ativar os tionofosforados, possibilitando o monitoramento de todos os organofosforados e carbamatos presentes na amostra. $\mathrm{O} \mathrm{pH}$ das amostras foi ajustado próximo da neutralidade com soluções diluídas de $\mathrm{NaOH}$ ou $\mathrm{HCl}$. O método analítico utilizado nas amostras de água foi o método do acetato de etila-sulfato de sódio para extração de organofosforados e carbamatos polares..$^{35} \mathrm{~A} 7 \mathrm{~mL}$ de cada amostra, adicionou-se $6 \mathrm{~g}$ de sulfato de sódio e agitou-se por $2 \mathrm{~min}$. Em seguida, foram adicionados $14 \mathrm{~mL}$ de acetato de etila e, após agitação e repouso para separação de fases, coletou-se $10 \mathrm{~mL}$ da fase acetato de etila. Os extratos foram evaporados sob corrente de nitrogênio até a secura, em banho-maria a $40^{\circ} \mathrm{C}$. Após evaporação acrescentou-se $0,25 \mathrm{~mL}$ da preparação enzimática (acetilcolinesterase) apropriadamente diluída, agitou-se fortemente e incubou-se durante $120 \mathrm{~min}$ a $37^{\circ} \mathrm{C}$. A seguir, foram adicionados $125 \mu \mathrm{L}$ da preparação incubada, $1,25 \mathrm{~mL}$ da solução do reagente de cor ditionitrobenzeno (DTNB) e $1,25 \mathrm{~mL}$ de solução do substrato da enzima (acetilcolina). A solução resultante foi transferida para a cubeta de espectrofotômetro (Cary 300, Varian ${ }^{\circledR}$ ) medindo-se o acréscimo de absorbância a cada minuto durante, pelo menos, $3 \mathrm{~min}$, no comprimento de onda $412 \mathrm{~nm}$. O mesmo procedimento foi realizado para a curva de calibração, a qual foi preparada com padrão de parationa metílica. Para esta avaliação, adotaram-se os parâmetros da Portaria n ${ }^{\circ} 518$ do Ministério da Saúde, de 25/4/2004, onde o valor máximo permitido de contaminação é de $20 \%$ de inibição da enzima acetilcolinesterase de mamíferos, que corresponde a $10 \mu \mathrm{g} / \mathrm{L}$ em equivalentes em parationa metílica. ${ }^{11} \mathrm{O}$ método analítico utilizado é extremamente prático e eficiente (coeficiente de variabilidade $<14 \%$, desvio da concentração esperada $<15 \%$, recuperação do método $88 \% \pm 2,6(\mathrm{DP}), \mathrm{n}=10$ no monitoramento de organofosforados e carbamatos (nível de detecção de $10 \mu \mathrm{g} / \mathrm{L}$ ), dada a facilidade de execução e o seu baixo custo. É extremamente improvável, especialmente após o processo extrativo das amostras, que possam ser encontrados interferentes que não sejam inibidores específicos da acetilcolinesterase. No entanto, não permite segregar as eventuais contaminações por princípio ativo dos agrotóxicos, sendo uma medida agregada da presença de organofosforados e carbamatos. $^{35}$

\section{RESULTADOS E DISCUSSÃO}

No município de Rondinha são cultivadas várias culturas como soja, milho, trigo, feijão e fumo. ${ }^{14}$ Em outubro de 2004, época da coleta das amostras de água, a única cultura em que estavam sendo aplicados inseticidas organofosforados era a de fumo, e na maioria das propriedades estas lavouras ficavam próximas de cursos de água (menos de $200 \mathrm{~m}$ ). Ao longo dos rios (Sarandi e Lambari) e dos arroios (Seco e Araçá) há mata ciliar; entretanto, na maioria dos pontos de coleta, próximos das lavouras de fumo, não era respeitada a metragem legal de $50 \mathrm{~m}$ nos rios e de $30 \mathrm{~m}$ nos arroios. ${ }^{36}$

De acordo com as informações obtidas com os agricultores das propriedades em que foram coletadas as amostras de água (pontos de coleta 2, 3, 4, 6, 7, 8, 10, 11, 12, 13, 14 e 15), o principal agrotóxico utilizado na cultura de fumo foi o inseticida acefato (Orthene ${ }^{\circledR}$ ), o qual pertence à classe toxicológica IV, ou seja, é considerado pouco tóxico. ${ }^{18}$ Todos os agricultores já haviam aplicado naquela safra de fumo o organofosforado acefato pelo menos uma vez até o mês de outubro e, segundo os mesmos, tal inseticida poderia ser aplicado de 1 a 4 vezes durante a mesma safra, conforme a necessidade. Em nenhuma das lavouras de fumo os agricultores haviam aplicado inseticidas carbamatos.

$\mathrm{O}$ acefato (O,S-dimetil-fosforoamidotioato, p.m. 183,16) é um sólido branco (pó solúvel) com ponto de fusão de 82 a $89{ }^{\circ} \mathrm{C}$ e apresenta solubilidade em água superior a $99,0 \% \mathrm{~m} / \mathrm{m}$. É estável em condições normais de manuseio e armazenamento e decompõe-se lentamente em meio ácido ou alcalino produzindo metamidofós, composto de elevada toxicidade e forte inibidor da acetilcolinesterase, que apresenta moderada persistência, tendo uma atividade residual em torno de 10 a 15 dias. $^{18}$

Na Tabela 2 são apresentados os dados relativos aos níveis de inseticidas inibidores da acetilcolinesterase detectados nas diversas amostras de água coletadas em rios, arroios e numa fonte de água mineral. Observa-se em cinco pontos de coleta $(1,2,10,11$ e 12) que estes níveis estão acima dos limites estabelecidos pela Portaria n 5 518/2004 (Ministério da Saúde), onde o valor máximo permitido de contaminação é de $20 \%$ de inibição da enzima acetilcolinesterase de mamíferos, que corresponde a $10 \mu \mathrm{g} / \mathrm{L}$ em equivalentes em parationa metílica. ${ }^{11}$ Os níveis de organofosforados detectados também estão acima dos limites estabelecidos pela legislação da União Européia. ${ }^{6,9}$

O alto nível de inibidores da acetilcolinesterase na amostra 1 (350 $\mu \mathrm{g} / \mathrm{L}$ ), coletada de uma fonte de água mineral, pode ser resultado da contaminação de cursos de água pelo lençol freático que alimenta a fonte, já que esta fica próxima da Linha Lambari (distância inferior a $1000 \mathrm{~m}$ ), uma das localidades com plantações de fumo. Análises em águas superficiais e subterrâneas, potencialmente utilizadas para consumo humano direto, na região da cultura do tomate em Paty do Alferes, Rio de Janeiro, detectaram contaminação por organofosfora-

Tabela 2. Níveis de inibidores da acetilcolinesterase detectados nas amostras coletadas

\begin{tabular}{lcc}
\hline Amostra & Pontos de coleta & $\begin{array}{c}\text { Concentração de inibidores da } \\
\text { acetilcolinesterase }(\mu \mathrm{g} / \mathrm{L})\end{array}$ \\
\hline 1 & Fonte de água mineral & 350 \\
$2 *$ & Rio Lambari & 40 \\
3 & Rio Lambari & $<10$ \\
4 & Rio Lambari & $<10$ \\
5 & Rio Lambari & $<10$ \\
$6 *$ & Rio Sarandi & $<10$ \\
7 & Rio Sarandi & $<10$ \\
8 & Rio Sarandi & $<10$ \\
9 & Rio Sarandi & 500 \\
$10 *$ & Arroio Seco & 500 \\
11 & Arroio Seco & 540 \\
12 & Arroio Seco & $<10$ \\
$13 *$ & Arroio Araçá & $<10$ \\
14 & Arroio Araçá & $<10$ \\
15 & Arroio Araçá & \\
\hline
\end{tabular}

* Amostras de água coletadas antes das plantações. 
dos e carbamatos em $70 \%$ dos pontos de coleta, e em duas amostras a contaminação estava acima do permitido pela legislação. ${ }^{17}$ Em outro estudo também foram detectados organofosforados em amostras de água potável coletadas em residências numa região de intensa atividade agrícola na Polônia. ${ }^{37}$ Devido à intercomunicabilidade dos sistemas hídricos, qualquer contaminação em um determinado sistema pode resultar em uma contaminação distante das áreas em que foram originalmente aplicados. Por isso, tal evento não representa apenas a contaminação da água consumida pela população local, mas também a contaminação de todas as pessoas abastecidas por esta água, ${ }^{17}$ como é o caso da água mineral obtida da fonte, localizada no centro da cidade, que é utilizada para consumo direto pela população.

Embora os pontos de coleta das amostras 11 e 12 ficassem a uma distância de $200 \mathrm{~m}$ das lavouras, as maiores concentrações de inibidores da acetilcolinesterase ( 500 e $540 \mu \mathrm{g} / \mathrm{L}$, respectivamente) na água superficial do Arroio Seco podem ser decorrentes da aplicação do acefato (Orthene ${ }^{\circledR}$ ) nas plantações de fumo uma semana antes da coleta das amostras. O solo desta região é classificado como Neossolo Litólico Distrófico, ou seja, tem uma baixa permeabilidade, sendo aumentada com as chuvas a infiltração da água no solo. ${ }^{13}$

Em um estudo realizado na região de Giza, Egito, amostras de solo próximas aos canais de água apresentaram concentrações de organofosforados maiores que as detectadas nas amostras de água. ${ }^{30}$ Como não foram analisadas amostras de solo em nosso estudo, não é possível realizar este tipo de comparação; no entanto, este tipo de análise auxiliaria a esclarecer a origem desta contaminação.

A contaminação detectada nos pontos de coleta $2(40 \mu \mathrm{g} / \mathrm{L})$ e 10 $(500 \mu \mathrm{g} / \mathrm{L})$, considerados pontos brancos, pode ser devida às chuvas intensas ocorridas nos dias anteriores à coleta das amostras e pouco tempo após a aplicação de agrotóxicos em lavouras próximas. Com isso pode ter ocorrido uma maior penetração de agrotóxicos no solo, contaminando os lençóis freáticos, ou os mesmos podem ter sido levados pelas águas das chuvas a locais mais distantes das plantações de fumo. Estes fatores podem ter contribuído também para o fato de 5 amostras apresentarem níveis de inibidores da acetilcolinesterase acima dos limites estabelecidos pela legislação. ${ }^{11}$

Outros estudos também indicaram para a presença de agrotóxicos nos sistemas hídricos, principalmente naqueles próximos de regiões agrícolas com intensa utilização destes produtos, tanto no Brasil ${ }^{5,17,38}$ como em outros países. ${ }^{7,831,39-42}$ A ocorrência de resíduos de organofosforados não é rara, como pode ser observado em estudos nos quais foram detectados tais resíduos nos Rios Alamo e New, nos Estados Unidos, ${ }^{8}$ no Rio Selangor, na Malásia, ${ }^{31}$ no Rio Reconquista, na Argentina, ${ }^{41}$ e em análises realizadas no Rio Ouémé, um dos rios mais importantes da República de Bénin. ${ }^{43}$

Desta forma, os resultados mostraram indícios de contaminação e do impacto da agricultura em diversos pontos dos cursos de água do município de Rondinha. Contudo, para esclarecer de forma inequívoca a origem desta contaminação, são necessárias novas investigações que incluam uma avaliação detalhada de outros usos possíveis de inibidores da acetilcolinesterase, além da cultura de fumo.

\section{CONCLUSÕES}

O uso de agrotóxicos pode contaminar os sistemas hídricos, resultando em uma série de consequiências adversas à saúde e alterações significativas nos ecossistemas. Os resultados apresentados neste estudo mostraram que 5 dos 15 pontos de coleta selecionados apresentaram contaminação detectável, o que confirmou a hipótese de que os organofosforados aplicados na agricultura podem contaminar os sistemas hídricos superficiais. De acordo com esses resultados ficou comprovada a contaminação por organofosforados em águas superficiais e em uma fonte de água mineral potencialmente utilizada para consumo humano direto no município de Rondinha.

Desse modo, há necessidade de realização de um monitoramento de longo prazo na área de estudo, a fim de identificar se a contaminação detectada foi casual ou persistente e como ela varia ao longo da safra. Estes estudos contribuirão para a avaliação da qualidade da água. Além disso, são necessárias ações planejadas da comunidade e do poder público. Estas ações devem ter como objetivo reduzir a possibilidade de contaminação dos sistemas hídricos e devem incluir a proteção das fontes de água subterrâneas e superficiais, a gestão e o manuseio correto dos agrotóxicos em áreas de produção rural, regulação estatal, programas de educação ambiental e adoção de práticas que minimizem os danos ao meio ambiente e a saúde humana.

\section{MATERIAL SUPLEMENTAR}

Disponível em http;//quimicanova.sbq.org.br, na forma de arquivo PDF, com acesso gratuito.

Nesse material é apresentada a Figura 1S - Mapa do município de Rondinha com a localização dos pontos de coleta de água.

\section{AGRADECIMENTOS}

Ao Laboratório Bioensaios, Viamão, Rio Grande do Sul, no qual foram realizadas as análises das amostras.

\section{REFERÊNCIAS}

1. Sperling, M. V.; Introdução à qualidade das águas e ao tratamento de esgotos, $2^{\text {a }}$ ed., Universidade Federal de Minas Gerais: Belo Horizonte, 1996, vol. 1.

2. Rio Grande do Sul, Ministério Público, Centro de Apoio Operacional de Defesa do Meio Ambiente; Coletânea de legislação ambiental, Procuradoria Geral de Justiça: Porto Alegre, 2003.

3. http://www.cetesb.sp.gov.br, acessada em Março 2007.

4. Losi-Guembarovski, R.; Santos, F. V.; Dias, F. L.; Frederico, R. G.; Cólus, I. M. S.; Food Chem. Toxicol. 2004, 42, 1245.

5. Marques, M. N.; Cotrim, M. B.; Pires, M. A. F.; Quim. Nova 2007, 30, 1171 .

6. Dores, E. F. G. C.; Freire, E. M. L.; Quim. Nova 2001, 24, 27.

7. Anderson, B. S.; Hunt, J. W.; Phillips, B. M.; Nicely, P. A.; Vlaming, V.; Connor, V.; Richard, N.; Tjeerdema, R. S.; Environ. Pollut. 2003, 124 , 523.

8. Vlaming, V.; DiGiorgio, C.; Fong, S.; Deanovic, L. A.; Carpio-Obeso, M. P.; Miller, J. L.; Miller, M. J.; Richard, N. J.; Environ. Pollut. 2004, $132,213$.

9. Silva, F. C.; Matos, A. R.; Carvalho, C. R.; Cardeal, Z. L.; Quim. Nova 1999, 22, 197.

10. http://www.who.int/water_sanitation_health/dwq/gdwq0506.pdf, acessada em Abril 2008.

11. Brasil, Ministério da Saúde, Portaria n. 518 de 25 de março de 2004. Estabelece os procedimentos e responsabilidades relativos ao controle e vigilância da qualidade da água para consumo humano e seu padrão de potabilidade, e dá outras providências; Diário Oficial da União, Brasília, DF, 2004

12. Brasil, Conselho Nacional do Meio Ambiente, Resolução n. 357, de 17 de março de 2005. Dispõe sobre a classificação dos corpos de água e diretrizes ambientais para o seu enquadramento, estabelece as condições e padrões de lançamento de efluentes; Congresso Nacional, Brasília, DF, 2005.

13. Buffon, J.; Emater/RS: caderno de dados básicos do Município de Rondinha/2003. Emater: Rondinha, 2003.

14. http://www.ibge.gov.br, acessada em Dezembro 2007.

15. Ferri, G. A.; Rondinha, Imagem Artes Gráficas: Chapada, 1988. 
16. http:/4.anvisa.gov.br/AGROSIA, acessada em Janeiro 2005.

17. Veiga, M. M.; Silva, D. M.; Veiga, L. B. E.; Castro-Faria, M. V.; Cad. Saúde Pública 2006, 22, 2391.

18. Larini, L.; Toxicologia dos praguicidas, Manole: São Paulo, 1999.

19. Oga, S.; Fundamentos de toxicologia, $2^{\text {a }}$ ed., Atheneu: São Paulo, 2003.

20. Devinsky, O.; Kernan, J.; Bear, D. M.; J. Neuropsychiatry Clin. Neurosci. 1992, 4, 189.

21. Bradwell, R. H.; Behavioural Neurology 1994, 7, 117.

22. Stallones, L.; Beseler, C.; Ann. Epidemiol. 2002, 12, 389.

23. Ruckart, P. Z.; Kakolewski, K.; Bove, F. J.; Kaye, W. E.; Environ. Health Perspect. 2004, 112, 46.

24. Kamel, F.; Engel, L. S.; Gladen, B. C.; Hoppin, J. A.; Alavanja, M. C.; Sandler, D. P.; Environ. Health Perspect. 2005, 113, 877.

25. Muller-Vahl, K. R.; Kolbe, H.; Dengler, R.; J. Neurol. Neurosurg. Psychiatry 1999, 66, 253.

26. Misra, U. K.; Nag, D.; Misra, N. K.; Human Toxicol. 1985, 4, 135.

27. Grover, I. S.; Malhi, P. K.; Mutat. Res. 1985, 155, 131.

28. Wei, L. Y.; Chao, J. S.; Hong, C. C.; Environ. Mol. Mutagen. 1997, 29, 386.

29. Tennant, A. H.; Peng, B.; Kligerman, A. D.; Mutat. Res. 2001, 493, 1.

30. El-Kabbany, S.; Rashed, M. M.; Zayed, M. A.; J. Hazard. Mater. 2000, 72,11 .

31. Leong, K. H.; Tan, L. L. B.; Mustafa, A. M.; Chemosphere 2007, 66, 1153.
32. Araújo, S. M. M.; Lemos, R. N. S.; Queiroz, M. E. R.; Nunes, G. S.; Pesticidas: R. Ecotoxicol. e Meio Ambiente 2001, 11, 115.

33. Franson, M. A. H.; Standard methods for the examination of water and wastewater, 20 ${ }^{\text {th }}$ ed., United Book Press: Baltimore, 1998.

34. http:/www.enparn.rn.gov.br, acessada em Janeiro 2005.

35. Castro-Faria, M. V. Em Avaliação de ambientes e produtos contaminados por agrotóxicos; Peres, F.; Moreira, J. C., eds.; Editora Fiocruz: Rio de Janeiro, 2003.

36. Brasil, Conselho Nacional do Meio Ambiente, Resolução n. 303, de 20 de março de 2002. Dispõe sobre parâmetros, definições e limites de Áreas de Preservação Permanente. Congresso Nacional, Brasília, DF, 2002.

37. Badach, H.; Nazimek, T.; Kaminska, I. A.; Ann. Agric. Environ. Med. 2007, 14, 109

38. Primel, E. G.; Zanella, R.; Kurz, M. H. S.; Gonçalves, F. F.; Machado, S. O.; Marchezan, E.; Quim. Nova 2005, 28, 605.

39. Payne, J. F.; Mathieu, A.; Melvin, W.; Fancey, L. L.; Mar. Pollut. Bull. 1996, 32, 225

40. Fries, E.; Püttmann, W.; J. Environ. Monit. 2001, 3, 621.

41. Rovedatti, M. G.; Castañé, P. M.; Topalián, M. L.; Salibián, A.; Water Res. 2001, 35, 3457.

42. Tariq, M. I.; Afzal, S.; Hussain, I.; Environ. Int. 2004, 30, 471.

43. Pazou, E. Y. A.; Boko, M.; Gestel, C. A. M.; Ahissou, H.; Lalèyè, P.; Akpona, S.; Hattum, B.; Swart, K.; Straalen, N. M.; Environ. Int. 2006, 32,616 . 


\section{AVALIAÇÃO DA CONTAMINAÇÃO POR ORGANOFOSFORADOS EM ÁGUAS SUPERFICIAIS NO MUNICÍPIO DE RONDINHA - RIO GRANDE DO SUL}

Francieli Três Griza*, Karen Saldanha Ortiz e Douglas Geremias

Instituto de Toxicologia, Pontifícia Universidade Católica do Rio Grande do Sul, Av. Ipiranga, 6681, 90619-900 Porto Alegre RS. Brasil

\section{Flávia Valladão Thiesen}

Faculdade de Farmácia e Instituto de Toxicologia, Pontifícia Universidade Católica do Rio Grande do Sul, Av. Ipiranga, 6681, 90619-900 Porto Alegre - RS, Brasil

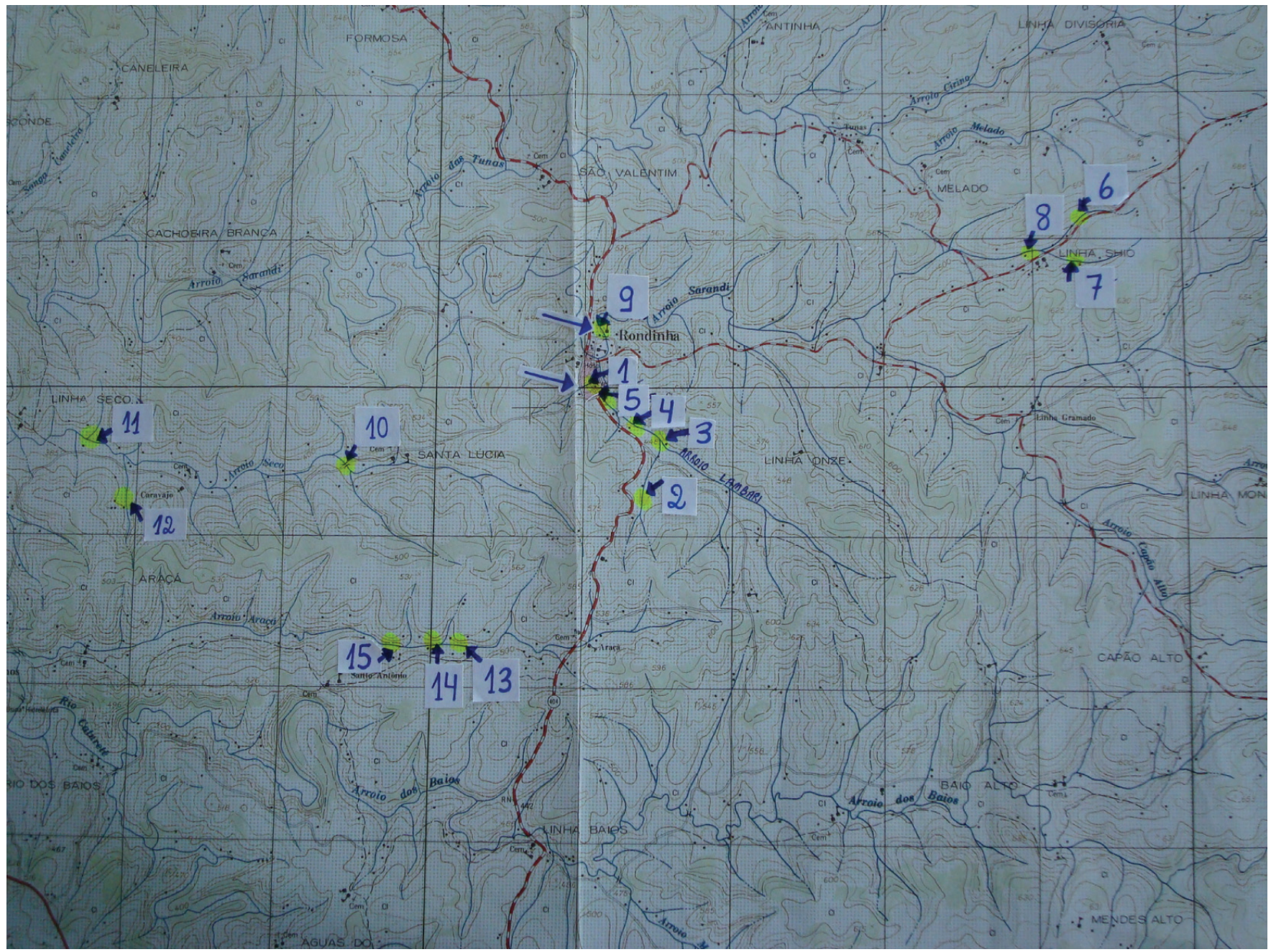

Figura 1S. Mapa do município de Rondinha com a localização dos pontos de coleta de água 1 a 15: Pontos de coleta de água

$\rightarrow$ : Pontos de captação de água da CORSAN 